\title{
Weapons Management in World Politics: An Introduction
}

\author{
J. DAVID SINGER \\ Research Political Scientist, University of Michigan
}

In the past few years, we have seen the birth and rapid growth of what almost amounts to an entire new field of intellectual activity. Reference is, of course, to that field which we have chosen here to call "weapons management," but which might as readily be labelled military policy, arms control, disarmament, or even peace research. Certainly the problems covered by this field are far from new; human groups have been arming, warring, disarming, and rearming with deadly regularity for centuries. The difference, however, is not in the problem, but in the approach to it.

Until World War II, the preparation for, conduct of, and recuperation from war was essentially a pre-scientific enterprise, as was the widespread effort to devise schemes for its amelioration or elimination. But during that last great war (the number of small ones since easily surpasses a dozen) two relatively new phenomena appeared; one was the rapid increase in the rate of technological innovation, and the other the emergence and acceptance of a mode of thought known as operations research, operations analysis, or systems analysis. Both played a signal role in the war, especially in the United Kingdom and the United States, and they have continued to exert a profound influence on the planning for World War III not only in these two nations but in many of the industrialized societies on both sides of the contemporary division.

It was not, however, until the mid-1950's that the intellectual style characterized by the operations analyst and his focus on manmachine systems was brought to bear in any significant way on problems which exceed the limited area of strategic bombing or sea-going or battlefield tactics. The applicability of these intellectual innovations to more large-scale problems during the past decade was demonstrated by two important developments in military procurement planning. One was the production planning scheme known as PERT (Production Evaluation and Review Technique) used to manipulate the thousands of variables affecting the design, testing, and ultimate production of the Polaris and other weapons systems. The other was in the field of military budgeting, exemplified in a study co-authored by the present Comptroller in the United States Department of Defense (Hitch and McKean, 1960). Once applied to these cumbersome social-planning problems, it was almost inevitable that these approaches would soon expand beyond the military preparedness field.

This they did, and in the arms control or weapons management area they were joined by another significant intellectual development: game theory. First fully articulated 
by Von Neumann and Morgenstern in 1947, it reached its most sophisticated strategic development in the work of Thomas Schelling (1960), Anatol Rapoport (1960), and Kenneth Boulding (1962). In due course these two strands of thought were to be joined by a rapid upsurge in the development of mathematical models for social science, and finally, by increasingly rigorous quantitative techniques for the gathering and interpreting of large-scale social and political data. Today, all of these intellectual streams are beginning to flow into an exciting and promising river of research on problems of war and peace. In a sense, intellectual innovation for war may have begun to contribute as much to planning for peace as technological innovation for war contributed to a massive increase in the range and complexity of peacetime consumer goods.

Now, none of these intellectual developments took place in a political vacuum; they were both a contribution to, and a result of, important strategic events. The most significant of these-and it is more a process than an event-was the growing awareness that the very brilliance of technological innovation in weapons design had made the use of these weapons increasingly dysfunctional for political purposes. By the late 1950's many military men were saying that if these weapons were ever used, they would have failed in their purpose; deterrence had become the sane man's "substitute for military victory." The most impressive indication that one major power had come to this realization was the creation, in the United States, of an Arms Control and Disarmament Agency.

As a consequence of these political trends, the ominous gap between the armers and the disarmers had begun to narrow. Preparedness in America was much less the private domain of the short-sighted jingoist and the opportunistic politician, and disarmament was much less the near-monopoly of the irrelevant utopian or pacifist. A common intellectual ferment was stirring-and recruiting-in both camps, and some tentative, muted dialogue was beginning to be heard. One promising indication was the accelerating appearance of scholarly writing, accentuated by the publication, in successive years, of two books which reflected the common intellectual advances, yet produced appreciably different policy conclusions (Snyder, 1961; Singer, 1962).

Another promising harbinger-in addition to the accelerated pace of scholarly research-was the organization of an increasing number of national and international conferences on arms control, disarmament, and peace research. Most of these meetings, of necessity, included both the armers and disarmers, and the dialogue was soon joined. Several of these were formal enough to require some of the participants to prepare papers in advance, and at least four of them ultimately led to the publication of those papers.

The first of these four was held at Endicott House outside of Boston in May of 1960. Sponsored by the American Academy of Arts and Sciences, and financed largely by the Johnson Foundation of Racine, Wisconsin, it led to the publication of a special issue of the Academy's quarterly Daedalus; this collection was later reissued under the editorship of Donald G. Brennan and published as Arms Control, Disarmament and National Security (Brennan, 1961). That same summer of 1960 saw the Academy (along with the Federation of American Scientists) sponsor a follow-up three-month Summer Study, eventuating in Arms Reduction: Program and Issues, edited by David H. Frisch and financed by the Twentieth Century Fund (Frisch, 1961).1

\footnotetext{
${ }^{1}$ The summer study, in which about 50
} 
In May, 1961, the American Assembly (with Ford Foundation support) devoted a three-day conference at Arden House in Harriman, New York, to the deterrence and disarmament problem, with the results appearing under Louis Henkin's editorship of Arms Control: Issues for the Public (Henkin, 1961). Then, in December, 1961, Seymour Melman organized a fourth symposium to eventuate in a serious publication. That meeting, held at Columbia University, sought to broaden both the agenda and the intellectual specialties represented, with the result explicitly reflected in the title of Disarmament: Its Politics and Economics, also published by the American Academy of Arts and Sciences (Melman, 1962).2

The present volume, then, is the fifth major one to emerge out of a conference on deterrence and disarmament, and it might be useful to describe that conference and compare its results with our predecessors, by way of justifying the publication of yet another arms control anthology. The International Arms Control Symposium (in the early planning it was Arms Control and Disarmament, but the omission developed somewhere along the way and found expression in thousands of brochures which were too timely and expensive to destroy) had its origins in a Faculty Seminar on Arms Control and Disarmament which be-

scholars and policy-makers participated at one time or another, also produced for limited circulation a pair of volumes known as the Collected Papers and Non-Physical Inspection Techniques. And at this writing another summer study (conducted at Wood's Hole in 1962 by the Institute for Defense Analyses for the Arms Control and Disarmament Agency) is scheduled for publication under the editorship of Richard J. Barnet and Richard A. Falk.

2 This volume, however, included only twenty papers presented, plus two which were added subsequently. gan at The University of Michigan in the summer of 1961, with the support of the Center for Research on Conflict Resolution and under the direction of Thomas Lough, Norman Thoburn, Stephen Withey, and myself. Originally conceived to initiate and accelerate arms control and disarmament research on the Michigan campus, the Seminar was soon enhanced by the attendance of several engineers and operations analysts from the Bendix Systems Division in Ann Arbor. These were people with a strong personal and professional commitment to the subject, a range of expertise nicely complementing that already present in the Seminar, and perhaps most crucial, an interest in finding financial support for their research. Combined with the University's Institute of Science and Technology, as well as scholars from other departments, these individuals were soon preparing research proposals for the Department of Defense and the Arms Control and Disarmament Agency, and before too long we had received several contracts from the latter.

Out of our ongoing contact with the Agency the subject of a "winter study" arose, with subsequent informal negotiation finally producing plans for a four-day symposium during the week before Christmas of 1962 . Under the general chairmanship of Russell O'Neal, Bendix Vice-President for Engineering, and Roger Heyns, Dean of the University's College of Literature, Science, and the Arts, the committee also included William P. Barth, Michael Radock, Norman Thoburn, and Cleland B. Wyllie from the University, and Phillip E. Chase, Robert G. Forman, Donald J. Ritchie, Daniel H. Schurz, and Ernest Van Valkenburg from Bendix. Responsible for the seven open, public sessions were Daniel C. Jones, of Bendix, and Elton B. McNeil, of the University's Department of Psychology, while 
John B. Teeple, of Bendix and I arranged the eighteen closed, technical panels. Leaving the background details, what general considerations guided the selection of topics, speakers, and discussants, and in what regard did they differ from those guiding our predecessors?

First of all, we had their experience to build upon and to help us appraise the strengths and weaknesses of the evolving weapons management field. From that appraisal, it seemed clear that the shift initiated by Melman fit well into changes that were already occurring both in international politics and the Western academic world. Dominant among those changes was the belatedly increasing role of social scientists. Whereas the emphasis in the Brennan, Frisch, and Henkin volumes was pretty much on the more directly relevant and short-run military stability problem, the Columbia conference explicitly sought a broadening out into the more long-range socio-economic and political realms. Moreover, the latter conference had a much higher number of social scientists participating than the seven, one, and four in the previous meetings, although only four of their papers were retained in the published proceedings. Thus, twenty-six of our forty-three authors were social scientists, and only two or three could be classified as psychologists, psychology being the discipline which has tended most often to be the social science representative in arms control and peace research activities. There were thirteen political scientists and five economists, and a sprinkling from sociology, history, and psychology. Another indication of the degree to which our predecessors have helped in advancing the field is the degree to which governmental policy-makers were involved. Whereas there were one, none, one, and two in the other four volumes, nine of our speakers and slightly more of our discussants came from a national government or the United Nations Secretariat. And whereas only nine, two, nine, and one representatives from industry are found in them, this conference had eleven speakers from the world of business. Clearly arms control and disarmament are no longer taboo in either government or industry.

This symposium differed from the others not only in composition but in the intellectual orientation of its speakers and discussants. We made no serious effort to cover all the problem areas in the deterrence-todisarmament field, or to achieve any sort of equitable balance between "hard liners" and "soft liners." Rather, we sought primarily a mix of innocence and realism, freshness and sophistication, so that the hard-soft dichotomy would be blurred in a problemoriented-as opposed to a policy-orientedcontext. For realism, we invited chairmen and discussants with a fair amount of research or policy experience in the subject field, or more often, a small notch or two away from that field. But for our speakerauthors, we quite consciously sought people-almost all of whom are scholars in either the university or industrial research setting - who had by no means reached the limits of what they could contribute to that problem area. Often these invitees were surprised by their assignments and occasionally they urged that they "knew nothing about it." Of course, the hope was that these protestations of ignorance were merely a reflection of the invitee's unfamiliarity with the particular way in which the problem was phrased, and that on further thought the relevance of their prior research would be evident. For the most part, we were not disappointed, even though we did experience the normal rate of turndowns.

Another advantage of these selection criteria was to produce a measure of uninhibit- 
edness which had seemed to be on the wane. Because a good many of the problems were relatively unexplored and because a large proportion of our authors were not yet caught up in the decision-making struggle (and one need not be in government, or even consulting for government, to become so enmeshed), the policy orientations were temporarily obscured. When neither the subject nor the speaker has yet been reduced to a policy pigeon-hole, and the line-up of agencies, offices and factions are still a matter of either ignorance or indifference, the tendency of the divisions to define the problem is markedly vitiated, to the benefit of fuller and more careful analysis.

Finally, this conference was able to do something which the forerunners would have found most difficult. Because of the degree of spadework which the Brennan, Frisch, Henkin, and Melman collections have accomplished, we were able to divert a considerable amount of our attention to matters of methodology. Though this was partly a luxury, it also seemed to be very much a necessity. Despite the impressive advances noted earlier, the arms control and disarmament field nevertheless seemed to be suffering from a double standard. When a scientist such as Jerome Wiesner calls for a high degree of rigor and precision in designing and evaluating weapons systems or surveillance devices, while classifying political and military problems as "too complicated for rational, logical solutions," and urging that they "admit of insights, not answers" (New Yorker, January 26, 1963, p. 60), it is clear that the social science-physical science gap is far from closed. This comment, plus many others in the scholarly and popular media, indicates that a large population of physical scientists and engineers as well as policy-makers believes that problems surrounding the behavior of large-scale social systems are not-and may never be-susceptible to scientific analysis. Thus, the promising trend noted at the outset seemed in danger of faltering, and as a consequence three panels were specifically intended to refute, or at least challenge, the emerging double standard, and in them we sought to raise some of the more awkward questions of observation, measurement, and conceptualization in the "policy sciences" (Lerner and Lasswell, 1951).

Though the seven papers in the final "Research Frontier" section may seem, at first blush, to have little relevance to the problem of weapons management, this impression would be correct only in the very short run, and then not in all cases. For example, the model employed in Rapoport's interpersonal experiment strongly suggests a parallel to contemporary bargaining, both at the conference table and in the ongoing exchange of bilateral threats and promises. Similarly, both the Crow and Davis studies represent an effort to replicate-in its essentials-the strategic bargaining and concomitant changes in tension level which are found to occur in "real" Soviet-American relations. All three of these papers may be thought of as attempts to simulate those segments of world politics which seem most germane to the probability of a stable deterrent relationship and a successfully negotiated disarmament system.

The fourth and fifth papers, on the other hand, seek to develop more sophisticated statistical techniques for dealing with the problem of compliance with a disarmament treaty. The approach found in the PattersonRichardson study is quite similar to the one now being explored by the Arms Control and Disarmament Agency in its attempts to calculate the degree of inspection reliability necessary to an adequate production cutoff treaty. In Ole Holsti's article, we find some 
promising advances toward the identification and measurement of one of the most crucial, but elusive, variables in international relations: tension. Finally, though Ralph Goldman's paper was originally presented under the domestic politics rubric, it is now set apart in this section because of its imaginative effort to formulate in more coherent and operational terms the vexing problem of the relationship between national and international politics. Both conceptually and (to a lesser extent) methodologically, it clearly points to the research frontier in the management of national weapons and international conflict.
In conclusion, this volume-and the symposium which it reflects-would seem to be a promising extension of those that have gone before. We have tried to build upon and to improve upon the impressive endeavors of our predecessors, and the reader will have to judge the measure of our success. If the enterprise has, in fact, met with some success, to that degree it may later be said that concerned men, combining the creativity and rigor of a scientific outlook with a lively sense of moral awareness, helped to deflect the nations from a path whose most likely terminal was nuclear holocaust. 